\title{
Mathematical modelling of intensified extraction for spent nuclear fuel reprocessing
}

\author{
Davide Bascone*, Panagiota Angeli, Eric S. Fraga \\ Centre for Process Systems Engineering, Department of Chemical Engineering, University College London (UCL), London WC1E 6BT, United Kingdom
}

\section{A R T I C L E I N F O}

\section{Keywords:}

Liquid-liquid extraction

Small channels

Spent nuclear fuel reprocessing

Optimisation

Process design

\begin{abstract}
A B S T R A C T
Small scale extractors seem to be a promising intensified alternative to the conventional solvent extraction technologies, because of the well described hydrodynamics, enhanced mass transfer, and good phase separation at the end. One of the most interesting applications of intensified extractions is the reprocessing of spent nuclear fuel. Operating in small channels can reduce the volumes of involved hazardous materials and the residence times, thus minimising the degradation of the solvent and its regeneration cost. Finally, nuclear criticality safety may be easily achieved.

In this paper, the application of small channels on spent nuclear fuel reprocessing has been investigated. A mathematical model of a multi-component liquid-liquid extraction has been developed. The multi-component system consists of $\mathrm{U}, \mathrm{Pu}, \mathrm{HNO}_{3}, \mathrm{HNO}_{2}, \mathrm{Zr}, \mathrm{Ru}, \mathrm{Tc}, \mathrm{Np}(\mathrm{IV}), \mathrm{Np}(\mathrm{V})$ and $\mathrm{Np}(\mathrm{VI})$, the organic solvent is a mixture of $30 \%(\mathrm{v} / \mathrm{v})$ Tri-Butyl Phosphate (TBP) and a paraffinic diluent. A segmented flow pattern, with the aqueous phase dispersed in a continuous organic phase, has been assumed. Calculations for the estimation of mass transfer, redox reactions, pressure drop, nuclear criticality and TBP hydrolysis have been included in the model. To increase the flow rates, the number of small channels was increased (scale out) and a comb-like manifold was considered to ensure good flow distribution in each channel. The problem is formulated as a mixed integer nonlinear programming problem and is implemented in the General Algebraic Modeling System (GAMS).

The results show that this alternative technology for liquid-liquid extraction offers advantages, especially in terms of solvent degradation and low holdup volume.
\end{abstract}

\section{Introduction}

Nuclear power is a low-carbon energy source which, due to the increasing concerns about global warming, continues to be an option for electricity generation. A major concern is the management of Spent Nuclear Fuel (SNF), which can remain toxic for hundreds of years. SNF consists of, approximately, $96 \%$ uranium and $1 \%$ plutonium, that can be reused (Todd, 2008). SNF reprocessing is beneficial to reduce volume and long-term radiotoxicity of high-level waste (IAEA, 2008).

Several studies on spent nuclear fuel have been done. Issues of concern include design of improved disposal concepts (Ahlstrm, 1997; Kim et al., 2014; Lee et al., 2012, transportation Jiang and Wang, 2016), alternative uses or technologies (Mohamed, 2014; Kim et al., 2013).

SNF, previously dissolved in a nitric acid solution, is extracted by TriButyl Phosphate (TBP) in the PUREX (Plutonium URanium EXtraction) process. Uranium and Plutonium are present, respectively, as $\mathrm{U}\left(\mathrm{VI}\right.$ ) (in the form of $\mathrm{UO}_{2}^{2+}$ ) and $\mathrm{Pu}\left(\mathrm{IV}\right.$ ) (in the form of $\mathrm{Pu}^{4+}$ ). These two components are extracted according to the following reactions:

$$
\begin{aligned}
& \mathrm{UO}_{2}^{2+}+2 \mathrm{NO}_{3}^{-}+2 \mathrm{TBP} \rightleftharpoons\left[\mathrm{UO}_{2}\left(\mathrm{NO}_{3}\right)_{2}\right] \cdot 2 \mathrm{TBP} \\
& \mathrm{Pu}^{4+}+4 \mathrm{NO}_{3}^{-}+2 \mathrm{TBP} \rightleftharpoons\left[\mathrm{Pu}\left(\mathrm{NO}_{3}\right)_{4}\right] \cdot 2 \mathrm{TBP}
\end{aligned}
$$

The reactions may be carried out in pulsed columns, mixer-settlers or centrifugal extractors. These technologies, however, have drawbacks including the need for large amounts of head space for pulsed columns, large floor space and poor geometry for criticality control for mixersettlers. Also, long solvent residence times are necessary, leading to solvent degradation. Centrifugal contactors are the most promising as a result of the short residence time and low holdup volume. However, their use is limited in industry since they are the least reliable of the three technologies, because of their poor tolerance to solids and need of periodic replacement of the motor and the rotor (Law and Todd, 2008).

Volume and solvent residence times may be significantly reduced if small scale extractors are used instead of columns and mixer settlers. The large surface area to volume ratio of small scale extractors can also address criticality issues. There are no moving parts and their diameter may be large enough to avoid occlusion; therefore, they can sufficiently

\footnotetext{
* Corresponding author.

E-mail address: davide.bascone.14@ucl.ac.uk (D. Bascone).
} 


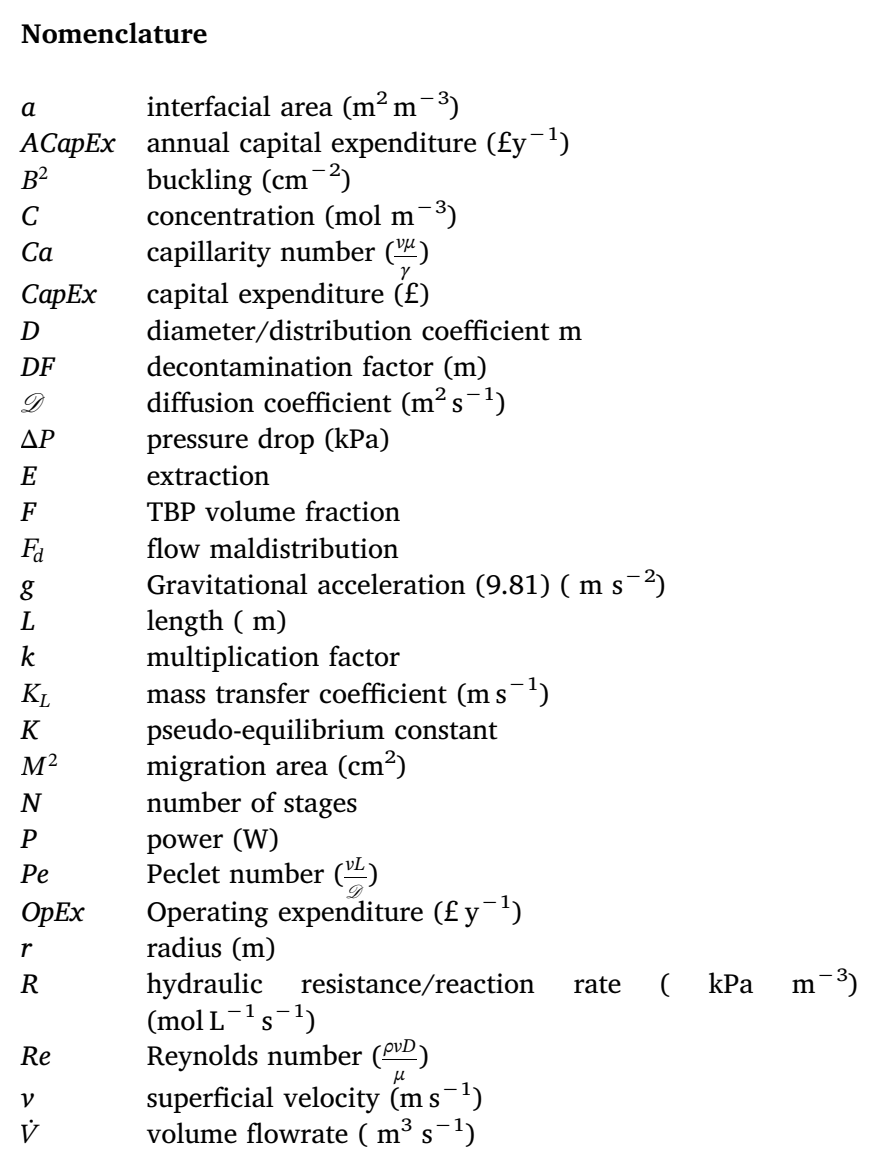

Greek symbols

$\alpha \quad$ ratio between disperse plug length and unit cell

$\gamma \quad$ Interfacial tension $\left(\mathrm{N} \mathrm{m}^{-1}\right)$
$\lambda_{N C} \quad$ non-circular coefficient

$\mu \quad$ viscosity (Pa s)

$\rho \quad$ mass density $\left(\mathrm{kg} \mathrm{m}^{-3}\right)$

$\theta \quad$ contact angle/correction factor for interfacial area $\left({ }^{\circ}\right)$

$\tau \quad$ temperature dependent function for distribution coefficient calculation

$\varphi \quad$ phase holdup

$\zeta \quad$ resistant coefficient

Subscripts and superscripts

$a q \quad$ aqueous phase

c continuous phase

ch channel

d dispersed phase

eff effective

eq equilibrium

fr frictional

$H \quad$ hydraulic

$i \quad$ generic index

in inlet

int interfacial

mix mixture

or organic phase

out outlet

tot total

UC unit cell

$\infty \quad$ infinite

\section{Acronysms}

GAMS general algebraic modeling system

PTFE polytetrafluoroethylene

PUREX plutonium uranium extraction

TBP tributyl phosphate tolerate solids unlike centrifugal contactors. Furthermore, mass transfer as well as mixing are significantly enhanced in small channels (Tsaoulidis and Angeli, 2015). The strategy of reducing the plant size without affecting the performance (which in this case may be even improved) is known as "process intensification" (Becht et al., 2009; Ramshaw, 1983; Cross and Ramshaw, 1986; Tsouris and Porcelli, 2003; Stankiewicz and Moulijn, 2000; Van Gerven and Stankiewicz, 2009).

Although many flow patterns can be achieved with biphasic flow in small scale contactors (Tsaoulidis et al., 2013), in this work segmented flow has been considered, which enhances two-phase mixing (Dore et al., 2012). In addition, in segmented flow, where one phase forms elongated drops (plugs) separated by continuous phase slugs, the hydrodynamics may be more easily controlled to improve mass transfer (Kashid and Agar, 2007; Tsaoulidis et al., 2013; Tsaoulidis et al., 2013; Tsaoulidis and Angeli, 2015). Hydrodynamics play a key role in these systems and, with an appropriate design, it is possible to:

- increase interfacial area;

- design phase separation at the end of the extractor; and,

- reduce pressure drop and, therefore, design more energetically efficient systems (Tsaoulidis et al., 2013).

Important plug flow characteristics, such as plug size and film thickness, have been investigated and several empirical correlations for predicting these parameters have been proposed (Leclerc et al., 2010; Xu et al., 2013). Models to predict pressure drop have been suggested as well (Kashid and Agar, 2007). Mass transfer in small channels has been investigated by several authors and equations to predict mass transfer coefficients for two-phase flows have been suggested (Kashid et al., 2010; Vandu et al., 2005).

There are only a few works on nuclear applications of liquid-liquid extraction in small channels (Tsaoulidis et al., 2013; Tsaoulidis et al., 2013; Tsaoulidis et al., 2013; Tsaoulidis and Angeli, 2015). Specifically, Tsaoulidis et al. (2013) and Tsaoulidis and Angeli (2015) studied the extraction of $\mathrm{U}(\mathrm{VI})$ in small channels from nitric acid solutions into a $30 \% \mathrm{v} / \mathrm{v}$ TBP and ionic liquid mixture, which is a potential alternative to the current organic diluent. They also developed a CFD model for the extraction of dioxouranium(IV) in segmented flow: in the 2-D axisymmetric model, the behaviour of a unit cell, i.e. one dispersed plug and one continuous slug, was investigated (Tsaoulidis and Angeli, 2015). Results predicted by the model were in good agreement with the experimental data.

In this paper, a model for the design of SNF reprocessing flowsheet using small channel extractors is presented. Extraction of uranium(VI), plutonium(IV), zirconium, technicium, ruthenium, neptunium, nitric and nitrous acid from a nitric acid solution into a 30\% v/v TBP/paraffinic diluent mixture is predicted. Distribution coefficients, mass transfer coefficients and pressure drop are estimated as suggested by the literature (Richardson and Swanson, 1975; Groenier, 1972; Asakura et al., 2005; Hongyan et al., 2017; Kumar and Koganti, 2001; Natarajan et al., 2012; Kashid and Agar, 2007; Kashid et al., 2010). Redox reactions between the three oxidation states of $\mathrm{Np}$ in nitric acid solutions have been included in agreement with the literature (Birkett et al., 2007; Hongyan et al., 2017; Tachimori, 1994). The design of the phase 
separator is performed as suggested by Scheiff et al. (2011). Furthermore, as the industrial use of small channels requires a very large number of parallel channels, the model includes the design of the distributors in the small channels and the collectors. In particular, the multi-scale flow network suggested by Commenge et al. has been considered (Commenge et al., 2011). The mathematical model has been used to define an optimisation-based design problem. The first section of the PUREX process has been optimised using the novel small channels technology, for varying channel sizes and operating variables. The above models have been adopted in this work, along with a differential mass balance model, to explore alternative flowsheets for SNF reprocessing.

\section{Mathematical model}

The mathematical model of the multi-component intensified extraction in small scale contactors, suitable for the SNF reprocessing, is presented below. Mass transfer, redox reactions, pressure drop, nuclear criticality and solvent degradation are considered. The design of the two-phase separator and manifolds are also included to scale out the process in many channels.

SNF is assumed to consist of U(VI), Pu(IV), Zr, Ru, Tc, Np(IV), Np(V) and $\mathrm{Np}(\mathrm{VI})$ dissolved in a $\mathrm{HNO}_{3}$ solution. $\mathrm{HNO}_{2}$, which is a degradation product of $\mathrm{HNO}_{3}$, is also considered.

Ideal plug flow conditions are assumed in the separation units for the development of the mass balance model. The following simplifying assumptions have been incorporated:

- complete mixing along the radial direction;

- no velocity gradient along the radial direction;

- constant volumetric flow rates throughout the channel;

- no axial mixing.

The plug flow condition is widely used for the estimation of the mass transfer coefficient in this systems (Tsaoulidis and Angeli, 2015; Tsaoulidis et al., 2013). Axial diffusion can be neglected, as the Peclet number is very low. A sketch of the plug flow model is shown in Fig. 1.

Steady state conditions have been assumed. Hence, the mass balance of the $i$ component in the $k$ phase is given by:

$-v_{k} \frac{d C_{i, k}}{d L}-K_{L} a\left(C_{i, k}-C_{i, k}^{e q}\right)+\sum R_{i, k} \varphi=0$

where $\sum R_{i, k} \varphi$ is the sum of all the chemical reactions, taking place in the phase $k$, involving the component $i$. Eq. (3) is solved numerically through the fourth order Runge-Kutta method and 50 grid points along the separation unit have been proven to be sufficient to solve this model accurately.

TBP can also extract a significant amount of $\mathrm{HNO}_{3}$, according to Richardson and Swanson (1975) and Groenier (1972):

$\mathrm{H}^{+}+\mathrm{NO}_{3}^{-}+\mathrm{TBP} \rightleftharpoons\left[\mathrm{HNO}_{3}\right] \cdot \mathrm{TBP}$

$\mathrm{H}^{+}+\mathrm{NO}_{3}^{-}+2 \mathrm{TBP} \rightleftharpoons\left[\mathrm{HNO}_{3}\right] \cdot 2 \mathrm{TBP}$

For the prediction of distribution coefficients of U(VI), $\mathrm{Pu}(\mathrm{IV})$ and
$\mathrm{HNO}_{3}$, Richardson's correlations have been used (Richardson and Swanson, 1975). These correlations take into account uranium, plutonium and TBP concentrations, as well as ionic strength and temperature.

Distribution coefficients of $\mathrm{Zr}$ and $\mathrm{Ru}$ have been calculated, with the empirical correlations proposed by Natarajan et al. (2012), as a function of the ionic strength. The distribution coefficient of Tc has been calculated as suggested by Asakura et al. (2005), which depends on uranium, plutonium, zirconium and TBP concentrations, ionic strength and temperature.

$\mathrm{Np}(\mathrm{IV})$ and $\mathrm{Np}(\mathrm{VI})$ are easily extractable. Their two-phase behaviour has been described as suggested by Benedict et al. (1980), but with the recalculated coefficients of Kumar and Koganti for the same database of 88 experimental points (Kumar and Koganti, 2001). Np(V) is almost unextractable; therefore, a nominal value of 0.01 has been used for its distribution coefficient (Hongyan et al., 2017). $\mathrm{HNO}_{2}$ is a product from nitric acid radiolysis, which affects Np redox kinetics. A concentration of $\mathrm{HNO}_{2}$ of $10^{-3} \mathrm{M}$ has been included in the feed to simulate its generation (Hongyan et al., 2017). Since it is extractable, the correlations suggested by Uchiyama (Uchiyama et al., 1998) have been used to describe the equilibrium of $\mathrm{HNO}_{2}$. All equations used to calculate the distribution coefficients are summarised in Appendix A.

The control of $\mathrm{Np}$ in the PUREX process is complex because its different oxidation states convert to each other while their thermodynamic behaviour is different, as discussed above. Reduction and oxidation reactions between $\mathrm{Np}(\mathrm{IV}), \mathrm{NP}(\mathrm{V})$ and $\mathrm{Np}(\mathrm{VI})$, in the aqueous and organic phases, have been included (Hongyan et al., 2017):

$\mathrm{NpO}_{2}^{+}+0.5 \mathrm{NO}_{3}^{-}+1.5 \mathrm{H}^{+} \rightleftharpoons \mathrm{NpO}_{2}^{2+}+0.5 \mathrm{HNO}_{2}+0.5 \mathrm{H}_{2} \mathrm{O}$

$2 \mathrm{NpO}_{2}^{+}+4 \mathrm{H}^{+} \rightleftharpoons \mathrm{Np}^{4+}+\mathrm{NpO}_{2}^{2+}+2 \mathrm{H}_{2} \mathrm{O}$

Details of the modelling of these chemical reactions are shown in Appendix B.

The overall volumetric mass transfer coefficient, i.e. the product between mass transfer coefficient $K_{L}$ and interfacial area $a$, has been calculated as suggested by Kashid et al. (2010), as a function of the channel diameter $D$ and length $L$ :

$K_{L} a=0.88 \frac{v_{\text {mix }}}{L} \mathrm{Ca}^{-0.09} \operatorname{Re}_{\text {mix }}^{-0.09}\left(\frac{D}{L}\right)^{-0.1}$

This equation seems to be the most appropriate for the current work among all the empirical and semi-empirical correlations proposed in the literature, since it exhibits a good agreement with experimental data of uranium extraction in small channels (Tsaoulidis and Angeli, 2015). The mass transfer model does not take into account variations in the phase flow ratio, which affect the interfacial area and therefore the value of $K_{L} a$. Instead, a correction factor $\theta$ has been included in the model,

$\theta=-0.511 \log \left(\frac{\dot{V}_{d}}{\dot{V}_{c}}\right)+0.9702$

based on experimental data from Tsaoulidis et al. (2013). Experiments showed that increasing the dispersed (aqueous) to continuous flow rate

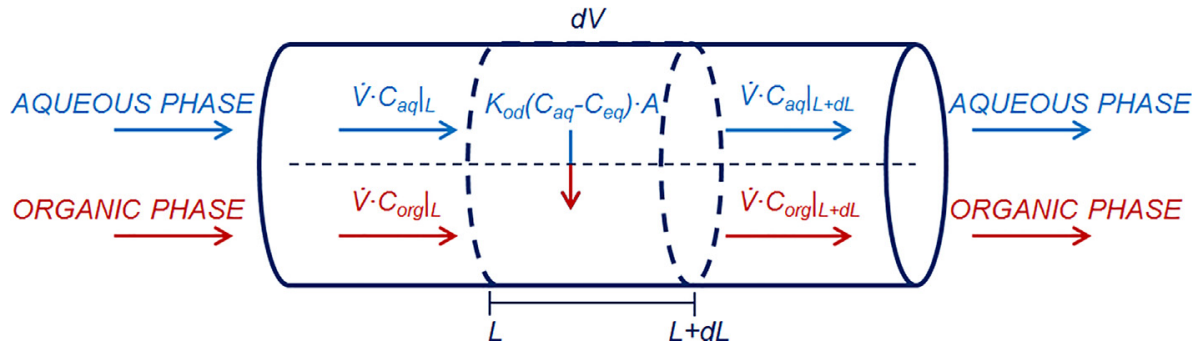

Fig. 1. Schematic diagram of the plug flow model. 
ratio improves the liquid-liquid interfacial area and therefore the extraction.

In the PUREX process, hydrolysis and radiolysis of TBP occur. The main degradation products are dibutylphosphoric acid and monobutylphosphoric acid, which reduce the separation efficiency of the process. A first estimate of the solvent degradation has been calculated assuming second order reactions, as suggested by Vladimirova et al. (1992). They initially estimate TBP hydrolysis in organic phase and in the presence of $\mathrm{Zr}$, and then calculate the proton concentration $\left[\mathrm{H}^{+}\right]$in the organic phase. Finally, they calculate the overall TBP hydrolysis, as shown in Appendix B. For further details, see Vladimirova et al. (1992). A first estimate of the TBP degradation may be interesting for the purpose of comparison with conventional technologies since the cost of solvent regeneration and cleanup can be significant.

To predict the pressure drop within the channel, the model developed by Kashid and Agar for two-phase liquid-liquid flows has been implemented (Kashid and Agar, 2007). They have calculated the overall pressure drop as the sum of frictional losses (Hagen-Poiseuille equation) and interfacial pressure drop (because of the dispersed phase).

An important impact on the overall pumping cost may be due to the singularity losses, in particular to the local pressure drop in the mixing junction, where the two streams are mixed before entering the small scale extractor. Singularity losses are often estimated using a resistance coefficient (Pan et al., 2009; Al-Rawashdeh et al., 2012). The resistance coefficient used in this work for the local pressure drop in the mixing junction, which is approximately equal to 4800 , has been obtained by fitting experimental data available in the literature for Y-junctions (Kashid et al., 2010). The calculation of all sources of pressure drop in this work is summarised in Appendix C.

The separation of the two phases at the end of the microchannel extractors can be achieved by exploiting differences in surface wettability between the aqueous and organic phases. If the aqueous phase is dispersed, the flow splitter can consist of a hydrophobic mainstream branch and a hydrophilic sidestream branch (such as stainless steel needles), and vice versa if the aqueous phase is continuous (hydrophilic mainstream, hydrophobic sidestream). The cost of the separator may significantly affect the economics of the overall equipment. In this work, the model suggested by Scheiff et al. (2011) to design this phase separator has been included. They have developed a pressure balance model, based on the Hagen-Poiseuille equation as Kashid and Agar (see Eqs. (44) and (45)), to separate dispersed plugs using a sidestream needle.

The design of the network for the distribution of the flow in the channels is essential to ensure reasonable pressure drop and flow uniformity. Many authors have investigated flow networks for micro or small devices, and the comb-like network seems to be the most appropriate because of the compact arrangement of small channels (Amador et al., 2004; Pan et al., 2008; Pan et al., 2009; Saber et al., 2009; Saber et al., 2010; Commenge et al., 2011; Al-Rawashdeh et al., 2012). The methodology developed by Commenge et al. (2011), based on a electrical resistances network model and assuming isothermal and laminar flow, has been used in this work.

Due to the large number of parallel channels, a four-level structure has been considered (see Fig. 2).

Levels 2, 3 and 4 regards the distribution and collection of the single phases, level 1 is where the two phases join and mass transfer occurs. Mixing junctions are required at the end of the level 2, as well as the separator at the end of the level 1 , which is shared between the two networks (one for each phase). For each level $i$, the hydraulic resistance $R$ is defined as:

$R_{i}=\frac{\Delta P_{i}}{\dot{V}_{i}}$

Assuming laminar flow, the Hagen-Poiseuille equation can be used to predict pressure drop in levels 2, 3 and 4 . Therefore, in the aforementioned levels, the hydraulic resistance of $R_{i}$, assuming non-circular channel, can be calculated as:

$R=\frac{32 \mu L_{i} \lambda_{N C}}{D_{H}^{2}} v$

where $\lambda_{N C}$ is the non-circularity coefficient and $D_{H}$ is the hydraulic diameter (for further details, see (Pan et al., 2009)). A square section is assumed, to simplify calculations.

Exploiting the electrical circuit analogy, a network considering the

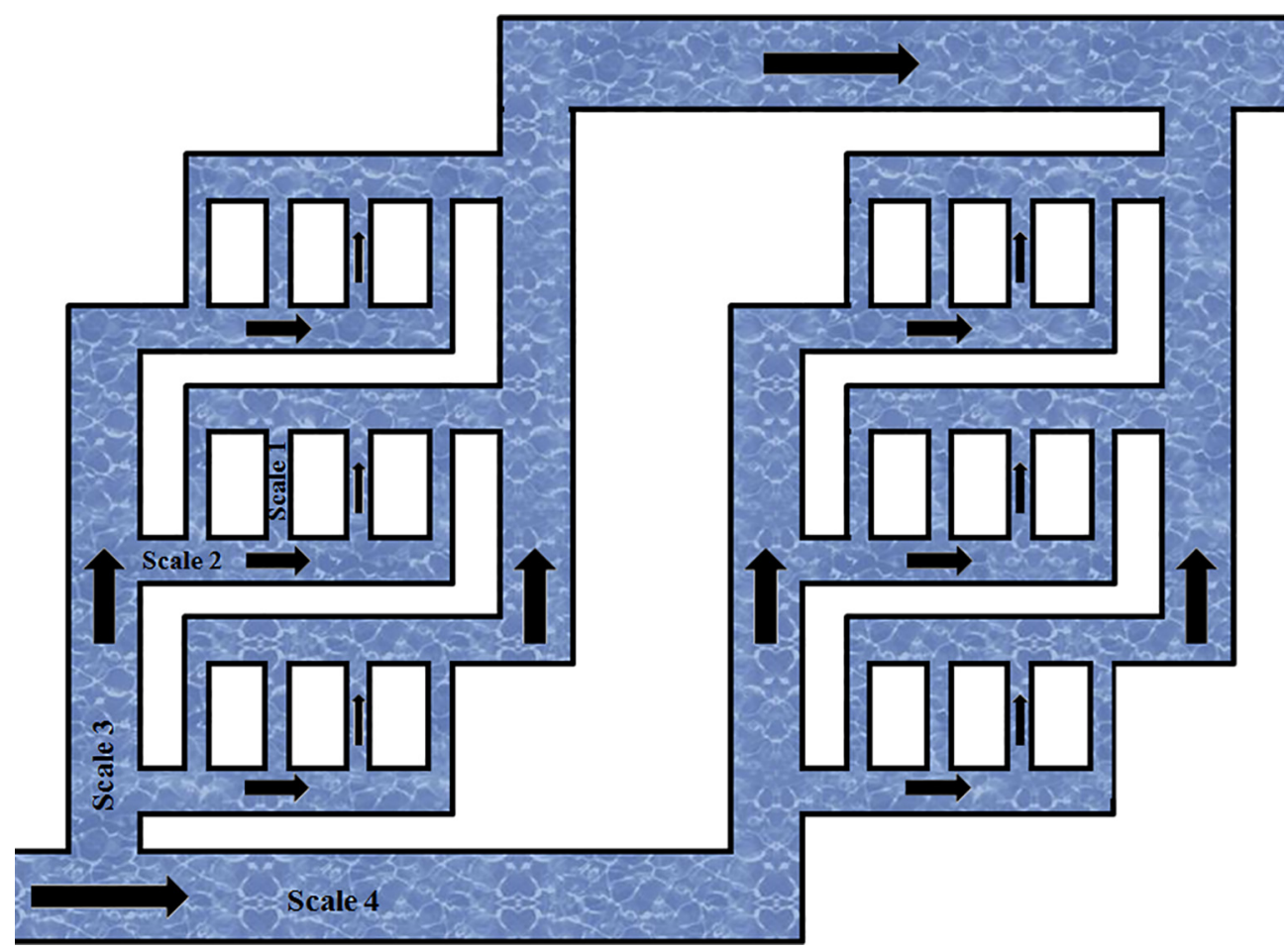

Fig. 2. Schematic of a four-level network. One element in level 4, two in level 3, three in level 2 and four in level 1, which is the small scale extractor, are shown. 
system up to the $n^{\text {th }}$ level may be described by the equivalent hydraulic resistance $R_{1 . n}$ :

$R_{1 . n}=\frac{\sum_{i=1}^{i=n} \Delta P_{i}}{\dot{V}_{n}}$

For instance, $R_{1.2}$ is the equivalent resistance of the sub-network involving a first and a second level, given by the ratio between the total $\Delta P$ in the first and the second levels the and volume flow rate entering the second level. Using the electrical analogy, the pressure drop can be easily calculated as the product of equivalent resistance and the volume flow rate (similarly to $V=R_{e q} \times I$ in the electrical system). The flow distribution depends on the pressure drops within the network, and therefore on the hydraulic resistances.

The resistance ratio $r$ is defined as the ratio between the equivalent resistance at one level and the resistance at the level above:

$r=\frac{R_{1 . n}}{R_{n+1}}$

Many definitions are used in the literature to quantify flow maldistribution $F d$. Commenge et al. use the maximum flow difference to the average one (Commenge et al., 2011). The global flow maldistribution can be calculated as $F d_{\text {global }}=1-\left(1-F d_{1}\right)\left(1-F d_{2}\right)\left(1-F d_{3}\right)$, where $F d_{1}, F d_{2}$ and $F d_{3}$ are the flow maldistributions in their respective levels. To simplify the calculations, the flow maldistribution is calculated by fitting the values provided by Commenge et al. as a function of the number of channels and the resistance ratio, rather than solving mass and pressure balance for each node of the network and its loops (the number of nodes is not fixed but depends on the optimal design of the flow network). A parabolic equation $F d=a N^{2}+b N$ is used, where $N$ here is the number of elements in the sub level and $a$ and $b$ are nonlinear functions of $r$.

Also, singularity losses in the manifolds, due to contraction, turning, splitting, combining and increase in the section area have been calculated using the resistance coefficients (Pan et al., 2009). These further pressure drops are used to calculate the total pressure drop in each level. However, apart from the first level where a significant pressure drop in the mixing zone occurs, these singularity losses are expected to be negligible if the Reynolds number is low. Hence, the total pressure drop, $\Delta P$, for pumping cost calculations includes:

- single phase frictional pressure drops in the distributing and collecting channels (i.e. levels 2, 3 and 4, see Fig. 2);

- singularity losses in the network, however they are expected to be negligible if laminar flow is established;

- the pressure drops in the mixing zone (assuming it is similar to the pressure drop in a Y-junction), this singularity loss is not negligible despite laminar regime;

- the pressure drop of the two-phase mixture in the extraction channel (level 1), given by frictional and interfacial pressure drops;

- the pressure drops in the mainstream and sidestream channels to achieve the phase separation.

To ensure safety with respect to nuclear criticality, the migrationarea approximation has been used to calculate the effective multiplication factor $k_{e f f}$, i.e. the ratio between the neutrons produced and those lost in any one generation, as follows (Carter et al., 1968):

$k_{\text {eff }}=\frac{k_{\infty}}{1+M^{2} B^{2}}$

Migration area $M^{2}$ and infinite multiplication factor $k_{\infty}$ are parameters provided by nuclear handbooks, as a function of uranium and plutonium concentrations in the solution (Carter et al., 1968). To simplify calculations, only values of $M^{2}$ and $k_{\infty}$ corresponding to the feed concentrations have been considered. This is the worst case, which involves the highest uranium and plutonium concentrations in the whole process. The buckling parameter $B^{2}$ depends on geometry and, for a cylindrical shape channel, is given by:

$B^{2}=\left[\frac{2.405}{r+\delta}\right]^{2}+\left[\frac{\pi}{L+2 \delta}\right]^{2}$

where $\delta$ is the extrapolation distance. This correlation does not take into account fission products and minor actinides, which are approximately $3 \%$ of the initial feed but highly active. Hence, minor actinides and fission products could significantly affect the $k_{\text {eff }}$, resulting in an underestimation of $k_{\text {eff }}$. Further and more detailed calculations would be required, Eq. (14) can provide an approximate estimation of the nuclear criticality risk. However, due to the very small holdup and the high surface area to volume ratio, the expected $k_{\text {eff }}$ using Eq. (14) is between 0.1 , in the small extractors, and between 0.3 and 0.5 in the distributors. Therefore, subcriticality is likely to be guaranteed, because of two reasons: the low values of $k_{\text {eff }}$ and the geometry of the small channels, also compared to the geometry and volume of conventional technologies used in this section of the PUREX, such as centrifugal extractors.

A single stage in not sufficient to meet the industrial requirements in terms of separation efficiency. Therefore, a multi stage counter-current design has been considered in this work. This flow configuration requires significantly less fresh solvent than a cross-flow design, whilst a co-current configuration is not practical. However, it is worth noting that this counter-current flow configuration only applies to the flow arrangement outside the channels; within the channels, the flows are co-current, as depicted in Fig. 3. Within each stage the flow is distributed to a number of channels using the distribution manifolds shown in Fig. 2.

The resulting mathematical model is a large mixed integer nonlinear programming problem and is implemented in the General Algebraic Modeling System (GAMS) (GAMS Development Corporation, 2013). Integer variables are the number of stages and the number of elements for each level of the network design. A summary of the optimisation problem is shown in Table 1.

\section{Case study and results}

The mathematical model has been employed to investigate the applicability of the intensified extraction in small channels in the first cycle of the PUREX process, the so-called "codecontamination" section, where $\mathrm{U}$ and $\mathrm{Pu}$ are separated from the other components in the SNF. In most modern flowsheets, the codecontamination section consists, mainly, of four extraction steps (Herbst et al., 2011):

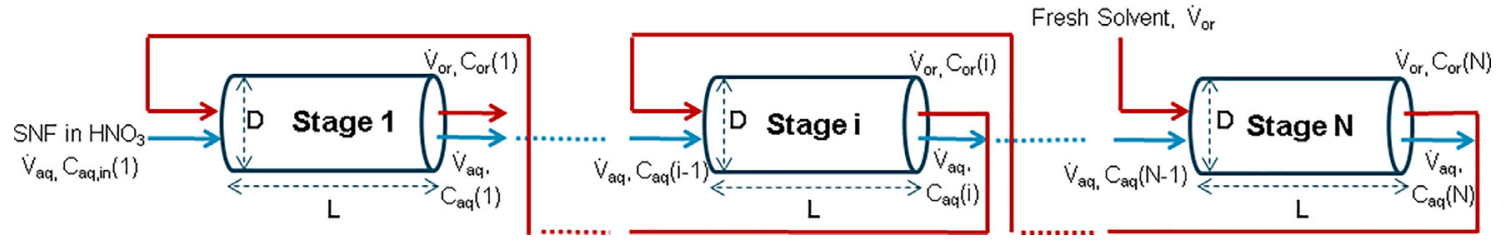

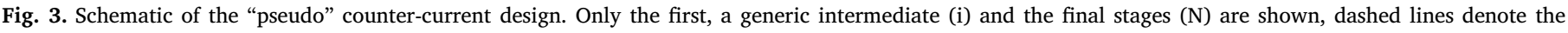
remaining stages between them. The blue streams refer to the aqueous phase, whereas the red streams refer to the organic phase. 
Table 1

Optimisation problem definition, including assumptions, free variables, requirements and constraints.

\begin{tabular}{lll}
\hline Given: & $\begin{array}{l}\text { Throughput, feed concentration, } \\
\text { temperature, channel material }\end{array}$ \\
Optimise: & $\begin{array}{l}\text { Design variables (No. of stages, No. of } \\
\text { elements of manifold, diameter or width } \\
\text { and length of each level), flow rates, }\end{array}$ \\
& $\mathrm{HNO}_{3}$ inlet concentration in aqueous \\
& streams & \\
So as to & Annualised total cost & \\
minimise: & & \\
Subject to: & Equality constraints: & Process model \\
& Inequality constraints: & {$[U]_{a q, o u t}^{\text {Mainextr }} \leqslant 1.68 \mathrm{M}$} \\
& & $E_{U} \geqslant 0.99$ \\
& $E_{P u} \geqslant 0.99$ \\
& $D F_{Z r} \geqslant 10^{4}$ \\
& $D F_{R u} \geqslant 10^{4}$ \\
& $D F_{T c} \geqslant 50$ \\
& $k_{\text {eff }} \leqslant 0.95$ \\
& $F_{d}^{\text {tot }} \leqslant 0.1$ \\
& $R e \leqslant 2000$
\end{tabular}

- main extraction (step 1), where $\mathrm{U}$ and Pu are separated from most of the other components in the SNF into an organic stream;

- $\mathrm{Zr}$ and Ru scrub (step 2), where a nitric acid solution is used to strip the extracted $\mathrm{Zr}$ and $\mathrm{Ru}$ (since $\mathrm{U}$ is also back extracted in this step, the aqueous stream is recycled to the main extraction step);

- Tc scrub (step 3), where a nitric acid solution is used to strip the extracted Tc from the organic stream, which is now ready for the partitioning and purification cycles of $\mathrm{U}$ and $\mathrm{Pu}$; and,

- complementary extraction (step 4), where fresh solvent is used to extract $\mathrm{U}$ and $\mathrm{Pu}$ stripped by the previous step, and the organic stream is recycled to the main extraction to increase the $U$ recovery.

A sketch of the flowsheet is shown in Fig. 4. The aim is to optimise the process, with regards to economic criteria, using the novel small scale contactor. The objective is to minimise the Total Annualised Cost $(T A C)$, which takes into account Operating Expenditure (OpEx) and Annualised Capital Expenditure (ACapEx):

$T A C=O p E x+A C a p E x$

The decision variables are both design (i.e. diameter or width and length of each channel in Fig. 2, number of stages, number of extraction channels to increase throughput and their arrangement in the network) and operating variables $\left(\mathrm{HNO}_{3}\right.$ concentration of all aqueous inlets, all flow rates except the aqueous feed). In this case study, channels are assumed to be hydrophobic, made of polytetrafluoroethylene (PTFE), so that the aqueous phase is dispersed. PTFE has been investigated and used for spent nuclear reprocessing, specifically for sieve plates in pulsed columns (Geier and Operation, 1957; Geier and Browne, 1977; Gonda et al., 1986). The cost of channels has been formulated as linear function of diameter/width and length, $\operatorname{CapEx}_{c h}=\left(k_{1} \times D+k_{2}\right) \times L$, with $k_{1}$ and $k_{2}$ constants. Cost for mixing junctions, considered fixed for each junction, is also included. The cost of manifolds is calculated, as a first estimation, as sum of channels cost and mixing junctions cost. All the costs are taken from CM Scientific Laboratory Supplies (CM Scientific, 2017), which provides transparent fluoropolymer channels for laboratory use, and have been reduced by one order of magnitude to convert the price to nontransparent polymer such as PTFE, taking into account typical market prices.

The operating expenditure is the cost for pumping power $P$, i.e. $P=\dot{V} \cdot \Delta P_{t o t} / \eta$ where $\eta$, the pump efficiency, is assumed to be 0.8 .

The flowsheet shown in Fig. 4 consists of approximately 365000 equations, involving nonlinear equations and integer variables. Furthermore, there are two recycle streams. Hence, long computational times and convergence difficulties are expected. These difficulties are circumvented, to some degree, by adopting a sequential modular approach first, that provides the initialisation for solving the entire flowsheet simultaneously later.

The mathematical model has been solved using the SBB (Simple Branch and Bound) solver; this has proven to be the most suitable for this model. A termination tolerance of $1 \%$ has been used for the optimisation.

\subsection{Comments on model}

The $4^{\text {th }}$ order Runge-Kutta numerical method has been used to solve the differential mass balance equations (Eq. (3)). Several attempts have been carried out to identify the appropriate number of grid points: coarser discretisation resulted in infeasible solutions, while 50 grid points were able to accurately reproduce the analytical solution (Eq. (3) can be analytically solved if no chemical reactions take place, i.e. for all components except neptunium). For annualised cost, a payout time is to be set. Treybal, investigated economic design of liquid extraction, using mixer-settlers, up to a 5-year payout time (Treybal, 1959). Smith reported typical values of the latter between 5 and 10 years (Smith, 2005). This process optimisation has been performed assuming a 5-year payout time. The optimisation problem has also been solved considering longer payout times, up to 10, and the optimal design has not been significantly affected.

The model has been built for channel diameters between 0.5 and $2 \mathrm{~mm}$. Eq. (8) was developed for diameters varying from 0.5 to $1 \mathrm{~mm}$ (Kashid et al., 2010), but is has been used in the literature to satisfactorily fit data up to a diameter of $2 \mathrm{~mm}$ (Tsaoulidis and Angeli, 2015). In this model, no further extrapolation of Eq. (8) has been performed.

The plug flow model seems to satisfactorily describe separation during segmented flow, because of the negligible axial dispersion. Hydrodynamics, in this orderly flow pattern, can be sufficiently predicted and therefore separation performance may be simply adjusted varying the flow rates within the channel or the length, to vary the residence time. Similarly, if redox kinetics are known, the Np behaviour may be easily predicted and its separation facilitated by the short residence time. The nature of the laminar flow pattern in small channels makes easier characterisation and modelling of the process, compared to the complex hydrodynamics and turbulent flows in the conventional technologies such as pulsed columns or mixer-settlers.

The typical concentration of TBP in the organic mixture has been considered, i.e. $30 \% \mathrm{v} / \mathrm{v}$. However the model could also be employed to investigate higher TBP concentrations, improving mass transfer and reducing volumes of organic streams and then equipment. The model could be also used with novel organic diluents; in this case different

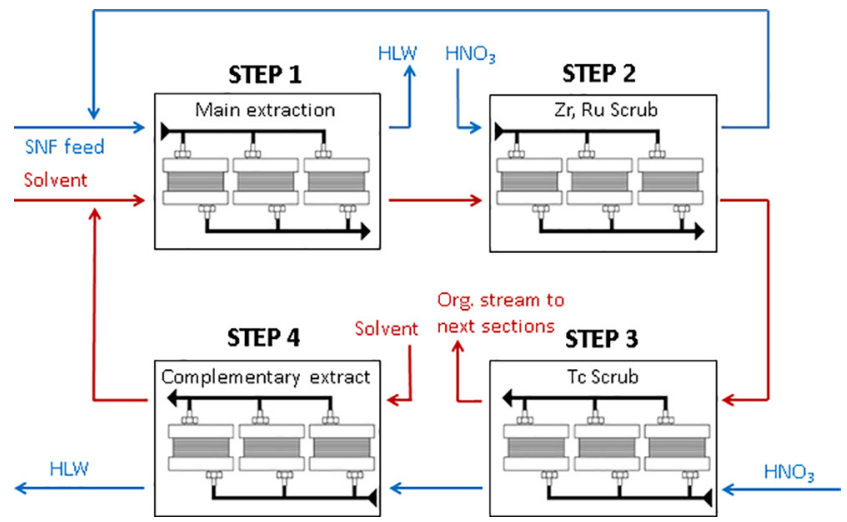

Fig. 4. Schematic of the flowsheet investigated in this work. Feed concentration: $\mathrm{U}(\mathrm{VI}) 250 \mathrm{~g} \mathrm{~L}^{-1}$, Pu(IV) $3 \mathrm{~g} \mathrm{~L}^{-1}, \mathrm{Zr} 1.18 \mathrm{~g} \mathrm{~L}^{-1}$, Ru $0.77 \mathrm{~g} \mathrm{~L}^{-1}$, Tc $0.27 \mathrm{~g}$ $\mathrm{L}^{-1}, \mathrm{~Np}(\mathrm{~V}) \mathrm{gL}^{-1} 0.15,\left[\mathrm{HNO}_{2}\right]=0.001 \mathrm{M}$. Throughput: $500 \mathrm{t}$ of heavy metal $\mathrm{y}^{-1}$. Solvent: $30 \%$ TBP/odorless kerosene (v/v). Temperature: $25^{\circ} \mathrm{C}$. 
distribution coefficients may need to be considered.

\subsection{Results}

An economic optimisation of the codecontamination section of the PUREX process has been performed. The minimum total annualised cost found is $£ 73,000 \mathrm{y}^{-1}$. Very limited data on economics of conventional technologies are available in the literature, because of industrial confidentiality reasons. In first approximation, based on typical sizes of pulsed columns used in the PUREX process $(12 \mathrm{~m}$ height, $0.3 \mathrm{~m}$ of diameter (Herbst et al., 2011)), a preliminary comparison can be done. According to the correlation provided by Seider et al. (2004), the capital cost of a column of the aforementioned dimensions is around $£ 200,000$. Annual operating cost, considering the hydraulic head and the power requirements for pulsation, is expected to be of the same order of magnitude of the capital cost. Hence the annualised total cost for a single pulsed column is approximately one order of magnitude higher than the one achieved in this work, using the small scale contactors, for the whole flowsheet.

Operating cost is approximately $10 \%$ of the total annualised cost because of the low pressure drops with optimal design and operating conditions. The main cause of pressure drop is associated with the mixing junctions, which can contribute by approximately $80 \%$ of the overall pressure drop. The design of the manifolds has a significant impact on the total capital cost: the manifolds constitute approximately $65 \%$ of the total cost. The cost for the two-phase separator itself is approximately $30 \%$, whilst the cost of the small extractor channels is negligible.

The optimal design of both channel and flow network, is shown in Table 2 and the optimal operating conditions are depicted in Table 3. The diameter takes the maximum value of those considered to minimise the number of parallel units, the length tends to the lower bound to maximise the overall volumetric mass transfer coefficient (see Eq. (8)), since most of the mass transfer occurs in the region close the mixing zone (Tsaoulidis and Angeli, 2015; Bascone et al., 2017).

The overall volumetric mass transfer coefficient is approximately $0.3 \mathrm{~s}^{-1}$ in all steps, higher than the same parameter reported in the literature for pulsed column operating with nitric acid solutions and TBP/paraffinic diluent (Qian et al., 1989; Jiao et al., 2013).

Nuclear criticality, due the large surface area to volume ratio provided by the small channels, does not appear to be an issue, with $k_{\text {eff }}$ sufficiently far from unity. This result, if confirmed by more detailed criticality calculations, suggests that the use of small channels may be investigated as an alternative to pulsed columns where mixer-settlers cannot be employed because of poor control of criticality.

An additional advantage of the use of small channels is the short residence times, of the order of seconds. Typical residence times for centrifugal contactors and pulsed columns are minutes, while for mixersettlers they are hours (Herbst et al., 2011). The residence time may affect the solvent degradation and, hence, solvent regeneration in the PUREX process.

Furthermore, a short residence time may affect the Np recovery. The $\mathrm{Np}$ control in the PUREX process is complex since, as discussed in Section 2, Np exists in this system in three different oxidation states,
Table 3

Optimal operating conditions.

\begin{tabular}{lllll}
\hline & Step 1 & Step 2 & Step 3 & Step 4 \\
\hline$\dot{V}_{\text {tot,aq }}$ inlet $\left[\mathrm{L} \mathrm{h}^{-1}\right]$ & 512 & 289 & 207 & 207 \\
$\dot{V}_{\text {totor }}$ inlet $\left[\mathrm{L} \mathrm{h}^{-1}\right]$ & 706 & 706 & 706 & 126 \\
$\mathrm{~A} / \mathrm{O}$ ratio & 0.7 & 0.4 & 0.3 & 1.6 \\
{$\left[\mathrm{HNO}^{3}\right]_{a q}$ inlet $[\mathrm{M}]$} & $3.6^{1}$ & 4.6 & 5.8 & 5.6 \\
\hline
\end{tabular}

${ }^{1}$ Concentration after recycle, $\mathrm{HNO}_{3}$ concentration in the feed is $2.5 \mathrm{M}$.

with different equilibrium behaviours. The value of Decontamination Factors $D F$ (the ratio between the amount of contaminant in the feed and the one in the product) achieved in this flowsheet is around 30, i.e. only approximately $5 \%$ of the Np present in the aqueous feed ends up in the organic product, as already mentioned (instead of the $75 \%$ in the typical process). The short residence time may explain this difference, since it does not allow high conversion from $\mathrm{Np}(\mathrm{V})$, unextractable, to $\mathrm{Np}(\mathrm{VI})$, very extractable. Np(IV) is also extractable, but its concentration seems to be negligible, according to the literature (negligible if $\mathrm{HNO}_{3}$ concentration is lower than $4 \mathrm{M}$, small if lower than $8 \mathrm{M}$ (Guillaume et al., 1984)).

Another benefit of the small channels is small volume of hazardous liquid involved. The extraction steps in the flowsheet investigated involve different liquid total volumes: approximately $220 \mathrm{~L}$ in step $1,80 \mathrm{~L}$ in step 2, $110 \mathrm{~L}$ in step 3 and $15 \mathrm{~L}$ in step 4 . These volumes may be further reduced by employing channel diameters above $2 \mathrm{~mm}$; in this case, however, mass transfer coefficients may significantly decrease. Furthermore, it is worth investigating an increase of TBP concentration in the organic phase, which could reduce volumes (the phase separation is based on the interfacial forces rather than gravitational, contrary to conventional technologies, hence having two phases of similar density, such as TBP and water, is not an issue and lower amounts of paraffinic diluent could be used), although viscosity and pressure drop will increase.

Predictions of separation performance and flow ratios seem reasonable: typical separation efficiency has been obtained (Herbst et al., 2011), with flow ratio similar to the one used by Gonda and Miyachi for main extraction in pulsed column (Gonda and Matsuda, 1986). For the scrubbing steps, low aqueous to organic flow ratios are expected, to minimise back extraction of $\mathrm{U}$ and Pu. The optimal number of stages is greater when a larger amount of $U$ and Pu must be extracted, as expected. These results may confirm the reliability of the benchmark equations integrated in the model, such as the Richardson's correlations for the modelling of the PUREX process (Richardson and Swanson, 1975). The outlet concentrations of each component of the SNF in the aqueous and organic phases are shown, respectively, in Table 4 and Table 5. The uncertainty in some distribution coefficients could affect these results: the correlations used for $\mathrm{Zr}$ and $\mathrm{Ru}$ do not take into account the presence of $\mathrm{U}$ and $\mathrm{Pu}$, but only depend on ionic strength. However, the concentration of $\mathrm{U}$ and $\mathrm{Pu}$ could affect the behaviour of $\mathrm{Zr}$ and Ru. Similarly, distribution coefficients of Np, in the model, are affected by concentrations of $\mathrm{U}$ and $\mathrm{Pu}$. Therefore, interactions between several components may not be taken into account. Also, the

Table 2

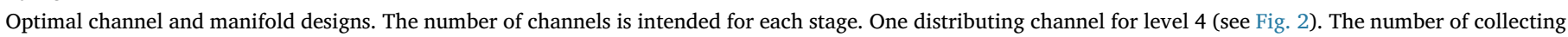
channels is equal to the number of distributing channel.

\begin{tabular}{|c|c|c|c|c|c|c|c|}
\hline & \multirow[t]{2}{*}{ No. stages } & \multirow[t]{2}{*}{$\mathrm{D}[\mathrm{mm}]$} & \multirow[t]{2}{*}{$\mathrm{L}[\mathrm{mm}]$} & \multirow[t]{2}{*}{ No. channels } & \multicolumn{3}{|c|}{ No. distributing channels } \\
\hline & & & & & Level 1 & Level 2 & Level 3 \\
\hline Step 1 & 4 & 2 & 100 & 5,280 & 48 & 11 & 10 \\
\hline Step 2 & 3 & 2 & 100 & 5,700 & 57 & 10 & 10 \\
\hline Step 3 & 3 & 2 & 100 & 4,264 & 41 & 13 & 8 \\
\hline Step 4 & 2 & 2 & 100 & 1,470 & 49 & 6 & 5 \\
\hline
\end{tabular}


Table 4

Outlet aqueous concentrations of metals, expressed as $\mathrm{gL}^{-1}$.

\begin{tabular}{lllll}
\hline & Step 1 & Step 2 & Step 3 & Step 4 \\
\hline $\mathrm{U}(\mathrm{VI})$ & $4.00 \times 10^{-1}$ & $1.86 \times 10$ & $1.40 \times 10$ & 1.66 \\
$\mathrm{Pu}(\mathrm{IV})$ & $5.37 \times 10^{-3}$ & $2.33 \times 10^{-1}$ & $1.47 \times 10^{-1}$ & $1.74 \times 10^{-2}$ \\
$\mathrm{Zr}$ & $5.16 \times 10^{-1}$ & $7.93 \times 10^{-2}$ & $7.71 \times 10^{-4}$ & $5.85 \times 10^{-4}$ \\
$\mathrm{Ru}$ & $3.35 \times 10^{-1}$ & $5.30 \times 10^{-3}$ & $6.64 \times 10^{-6}$ & $6.56 \times 10^{-6}$ \\
$\mathrm{Tc}$ & $9.75 \times 10^{-2}$ & $3.52 \times 10^{-1}$ & $4.74 \times 10^{-2}$ & $4.61 \times 10^{-2}$ \\
$\mathrm{~Np}(\mathrm{IV})$ & $3.85 \times 10^{-8}$ & $1.35 \times 10^{-7}$ & $3.63 \times 10^{-8}$ & $1.11 \times 10^{-8}$ \\
$\mathrm{~Np}(\mathrm{~V})$ & $6.39 \times 10^{-2}$ & $1.62 \times 10^{-3}$ & $1.78 \times 10^{-5}$ & $2.27 \times 10^{-5}$ \\
$\mathrm{~Np}(\mathrm{VI})$ & $1.66 \times 10^{-4}$ & $7.98 \times 10^{-4}$ & $5.51 \times 10^{-4}$ & $7.80 \times 10^{-5}$ \\
\hline
\end{tabular}

Table 5

Outlet organic concentrations of metals, expressed as $\mathrm{gL}^{-1}$.

\begin{tabular}{lllll}
\hline & Step 1 & Step 2 & Step 3 & Step 4 \\
\hline $\mathrm{U}(\mathrm{VI})$ & $9.01 \times 10$ & $8.25 \times 10$ & $7.84 \times 10$ & $2.02 \times 10$ \\
$\mathrm{Pu}(\mathrm{IV})$ & 1.03 & $9.35 \times 10^{-1}$ & $8.92 \times 10^{-1}$ & $2.13 \times 10^{-1}$ \\
$\mathrm{Zr}$ & $3.27 \times 10^{-2}$ & $2.64 \times 10^{-4}$ & $3.75 \times 10^{-5}$ & $3.05 \times 10^{-4}$ \\
$\mathrm{Ru}$ & $2.17 \times 10^{-3}$ & $1.95 \times 10^{-6}$ & 0 & $1.25 \times 10^{-7}$ \\
$\mathrm{Tc}$ & $1.59 \times 10^{-1}$ & $1.56 \times 10^{-2}$ & $1.72 \times 10^{-3}$ & $2.01 \times 10^{-3}$ \\
$\mathrm{~Np}(\mathrm{IV})$ & $8.77 \times 10^{-8}$ & $3.26 \times 10^{-8}$ & $2.19 \times 10^{-8}$ & $4.15 \times 10^{-8}$ \\
$\mathrm{~Np}(\mathrm{~V})$ & $6.63 \times 10^{-4}$ & $8.14 \times 10^{-7}$ & $1.45 \times 10^{-8}$ & $1.91 \times 10^{-7}$ \\
$\mathrm{~Np}(\mathrm{VI})$ & $2.06 \times 10^{-3}$ & $1.74 \times 10^{-3}$ & $1.57 \times 10^{-3}$ & $7.69 \times 10^{-4}$ \\
\hline
\end{tabular}

correlation used to predict the mass transfer coefficient, which is assumed to be the same for all components, has been developed for a different solute, hence the values of parameters in Eq. (8) may need to be recalculated with the current system. However, because of lack of information in the literature, original parameters have been used. These uncertainties could lead to an overestimation of the mass transfer, and hence to overestimated separation and underestimated dimensions.

Regarding the robustness of the mathematical model, it is a large nonlinear model which includes integer variables and recycle streams, therefore a proper initialisation is required. The initialisation may significantly affect the optimal result.

\section{Conclusions}

A mathematical model of a multi-component liquid-liquid extraction in small channels for reprocessing of spent nuclear fuel has been developed. The design of distributors, collectors and two-phase separators is included in this model. Redox reactions between the three existing oxidation states of $\mathrm{Np}$ in nitric acid solutions have been included, as well as an estimation of pressure drop, solvent hydrolysis and nuclear criticality. To demonstrate the potential use of this model, a case study of the codecontamination section of the PUREX process, has been addressed. The resulting design problem, a large scale nonlinear model (approximately 365,000 equations), has been formulated as a mixed-integer nonlinear programme and implemented in the GAMS modelling system. The results show that the use of small scale extraction technology may be advantageous in terms of residence time, plant size and neptunium control.

The mathematical model, despite the large size and the highly nonlinearity of some equations, has provided reasonable results and short computational time, when properly inizialised. It combines the simplicity of a one-dimensional plug flow model and the reliability of well-known equations to deliver a tool for process design based on laboratory prototypes. It could also be the starting point for developing more detailed and customised models for liquid-liquid extraction in small channels, including different components and solvents.

\section{Acknowledgements}

The authors would like to acknowledge the UK Engineering and Physical Sciences Research Council (EPSRC) for funding provided as the PACIFIC project, EP/L018616/1. D.Bascone would also like to thank University College London for his studentship.

\section{Appendix A. Calculation of distribution coefficients}

Distribution coefficient of U(VI) is given by the equation:

$D_{U}=K_{U}[T B P]_{o r}^{2}$

where $[T B P]_{o r}$ is the free, i.e. unbounded, TBP concentration in the organic phase. The pseudo-equilibrium constant $K_{U}$ is calculated by the following expression (Richardson and Swanson, 1975):

$K_{U}=\left(3.7\left[\mathrm{NO}_{3}^{-}\right]_{a q}^{1.57}+1.4\left[\mathrm{NO}_{3}^{-}\right]_{a q}^{3.9}+0.011\left[\mathrm{NO}_{3}^{-}\right]_{a q}^{7.3}\right)\left(4 \mathrm{~F}^{-0.17}-3\right) e^{2500 \tau}$

where $\tau$ is the temperature-dependent function as follows:

$\tau=\frac{1}{T}-\frac{1}{298}$

Similarly, distribution coefficient and pseudo-equilibrium constant of $\mathrm{Pu}(\mathrm{IV})$ and $\mathrm{HNO}_{3}$ depends on ionic strength [NO$\left.{ }_{3}^{-}\right]$, TBP concentration and temperature:

$D_{P u}=K_{P u}[T B P]_{o r}^{2}$

$K_{P u}=K_{U}\left(0.20+0.55 F^{1.25}+0.0074\left[N O_{3}^{-}\right]_{a q}^{2}\right)\left(4 F^{-0.17}-3\right) e^{-200 \tau}$

$D_{H 1}=K_{H 1}[T B P]_{o r}$

$D_{H 2}=K_{H 2}[T B P]_{o r}^{2}$

$K_{H 1}=\left(0.135\left[\mathrm{NO}_{3}^{-}\right]_{a q}^{0.85}+0.005\left[\mathrm{NO}_{3}^{-}\right]_{a q}^{3.44}\right)\left(1-0.54 e^{-15 F} e^{340 \tau}\right)$

$K_{H 1}=K_{H 2}$

where the subscripts $H 1$ and $H 2$ refer to the form of the nitric acid in the organic phase as illustrated, respectively, by Eqs. (4) and (5).

Distribution coefficients of $\mathrm{Zr}$ and Ru have been calculated as follows (Natarajan et al., 2012):

$D_{Z r}=K_{Z r}[T B P]_{o r}^{2}$ 
$\ln K_{Z r}=0.2685\left[\mathrm{NO}_{3}^{-}\right]_{a q}^{2}-0.6359\left[\mathrm{NO}_{3}^{-}\right]_{a q}+0.4853$

$D_{R u}=K_{R u}[T B P]_{o r}^{2}$

$\ln K_{Z r}=-0.0691\left[N_{3}^{-}\right]_{a q}^{3} 0.8356\left[N_{3}^{-}\right]_{a q}^{2}-2.3672\left[N O_{3}^{-}\right]_{a q}+0.9165$

The equilibrium phase behaviour of technetium is estimated as suggested by Asakura et al. (2005):

$D_{T c}=D_{T c, 0}+D_{T c, U}+D_{T c, P u}+D_{T c, Z r}$

$D_{T c, 0}=0.845[\mathrm{TBP}]_{o r}^{1.92 e^{3300 \tau}} \frac{2.324\left[\mathrm{NO}_{3}^{-}\right]_{a q}^{0.848 e^{230 \tau}} e^{8070 \tau} e^{-350 \tau}}{1+0.157\left[\mathrm{NO}_{3}^{-}\right]_{a q}^{4.69 e^{410 \tau}} e^{324 \tau}+1.72\left[\mathrm{NO}_{3}^{-}\right]_{a q}^{1.95 e^{160 \tau}} e^{3150 \tau}}$

$D_{T c, U}=0.331 \frac{\left[\mathrm{UO}_{2}^{2+}\right]_{o r}}{\left[\mathrm{UO}_{2}^{2+}\right]_{o r}+\left[\mathrm{Pu}^{4+}\right]_{o r}}\left\{1+4.87\left[\mathrm{NO}_{3}^{-}\right]_{a q}^{-1.343} e^{980 \tau}\right\} e^{-1060 \tau}$

$D_{T c, P u}=3.31\left[\mathrm{NO}_{3}^{-}\right]_{a q}^{-0.707} \frac{\left[U O_{2}^{2+}\right]_{o r}}{\left[U O_{2}^{2+}\right]_{o r}+\left[\mathrm{Pu}^{4+}\right]_{o r}} e^{-1060 \tau}$

$D_{T c, Z r}=1670[\mathrm{Zr}]_{o r}\left[\mathrm{NO}_{3}^{-}\right]_{a q}^{-0.707} e^{2810 \tau}$

Distribution coefficient of $\mathrm{Np}(\mathrm{IV})$ and $\mathrm{Np}(\mathrm{VI})$ are estimated as follows (Benedict et al., 1980; Kumar and Koganti, 2001):

$D_{N p(V I)}=0.52768 D_{U}$

$D_{N p(I V)}=1.109 \cdot 10^{-7} e^{0.29623\left[\mathrm{NO}_{3}^{-}\right] \mathrm{aq}+0.041519 T} D_{U}$

The following correlation has been used to calculate the distribution coefficients of $\mathrm{HNO}_{2}$ (Uchiyama et al., 1998):

$D_{\mathrm{HNO}_{2}}=25[\mathrm{TBP}]_{\text {or }}$

\section{Appendix B. Calculation of chemical reactions}

Kinetic reaction of Eq. (6) is given by Koltunov (1974) and Hongyan et al. (2017):

$$
\begin{aligned}
-\frac{d[N p(V)]_{a q}}{d t}= & 2.884 \times 10^{11} e^{-\frac{9922}{T}}[\mathrm{~Np}(\mathrm{~V})]_{a q}\left[\mathrm{HNO}_{2}\right]_{a q}^{0.5}\left[\mathrm{H}^{+}\right]_{a q}^{z}\left[\mathrm{NO}_{3}^{-}\right]_{a q} \\
& +5.405 \times 10^{12} e^{-\frac{10031}{T}}[\mathrm{~Np}(\mathrm{~V})]_{a q}\left[\mathrm{HNO}_{2}\right]_{a q}\left[\mathrm{H}^{+}\right]_{a q} \\
-\frac{d[N p(V I)]_{a q}}{d t}= & 2 \times 6.928 \times 10^{10} e^{-\frac{7505}{T}}[\mathrm{~Np}(\mathrm{VI})]_{a q}\left[\mathrm{HNO}_{2}\right]_{a q}\left[\mathrm{H}^{+}\right]_{a q}^{-1} \\
& +2 \times 2.497 \times 10^{12} e^{-\frac{7806}{T}}[\mathrm{~Np}(\mathrm{VI})]_{a q}\left[\mathrm{HNO}_{2}\right]_{a q}^{1.5}\left[\mathrm{H}^{+}\right]_{a q}^{-0.5}\left[\mathrm{NO}_{3}^{-}\right]_{a q}^{-0.5}
\end{aligned}
$$

In Eq. (37), the most suitable value of the exponent $z$, for nitrous acid concentration of around $10^{-3} \mathrm{M}$, seems to be 2 (Birkett et al., 2007). The kinetic law for Eq. (7) is taken from Tachimori (1994):

$-\frac{d[N p(V)]_{a q}}{d t}=4.1667 \times 10^{-2}[N p(V I)]_{a q}^{2}\left[H^{+}\right]_{a q}^{2}$

$-\frac{d[N p(I V)]_{a q}}{d t}=1.3333 \times 10^{-5}[N p(I V)]_{a q}[N p(V I)]_{a q}\left(2.16+12.5\left[N O_{3}^{-}\right]_{a q}\right)$

The $\mathrm{Np}(\mathrm{V})$ oxidation in the organic phase has been considered, as well. However, contrarily to Eq. (6), it is assumed to be only a forward reaction from $\mathrm{Np}(\mathrm{V})$ to $\mathrm{Np}(\mathrm{VI})$ (Hongyan et al., 2017):

$-\frac{d[N p(V)]_{o r}}{d t}=1.952 \times 10^{11} e^{-\frac{9008}{T}}[N p(V)]_{o r}\left[H_{N O}\right]_{a q}^{0.5}\left[H^{+}\right]_{a q}^{0.5}\left[H_{2} \mathrm{O}\right]_{o r}^{-0.2}$

where water solubility in organic phase is fixed to $0.42 \mathrm{M}$ (Hongyan et al., 2017).

The overall TBP hydrolysis is calculated as follows:

$-\frac{d[T B P]_{o r}}{d t}=5.5556 \times 10^{-9}\left(\left[H^{+}\right]_{o r}[T B P]_{o r}+q K_{a q}\left[H^{+}\right]_{a q}[T B P]_{a q}\right)$

The kinetic constant shown in Eq. (42) has been calculated at $25^{\circ} \mathrm{C}$, from the Arrhenius plot of the kinetic constants and temperatures provided by Vladimirova et al. (1992). All reaction rates above have been expressed in $\mathrm{mol} \mathrm{L}^{-1} \mathrm{~s}^{-1}$.

\section{Appendix C. Calculation of pressure drops}

The pressure drop within the small channels is calculated as:

$\Delta P_{\text {tot }}=\Delta P_{f r, a q}+\Delta P_{f r, o r g}+\Delta P_{\text {int }}$

where $\Delta P_{f r}$ and $\Delta P_{\text {int }}$ are calculated as suggested by Kashid and Agar (2007): 
$\Delta P_{f r, a q}=\frac{8 \mu_{a q} v_{m i x} \alpha L_{U C}}{r^{2}}$

$\Delta P_{f r, o r g}=\frac{8 \mu_{o r} v_{m i x}(1-\alpha) L_{U C}}{r^{2}}$

$\Delta P_{i n t}=\frac{2 \gamma}{r} \cos \theta$

The values of $L_{U C}$ and $\alpha$, i.e. the ratio between plug length and cell length, is a function to the fluid velocity and channel geometry. However,

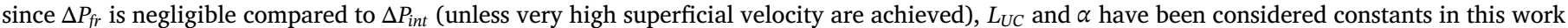

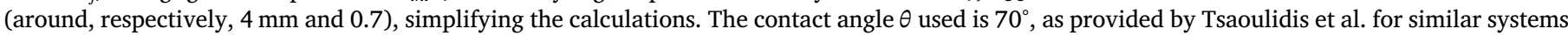
(Tsaoulidis et al., 2013).

Singularity losses due to mixing, due to contraction, turning, splitting, combining and increase in the section area are calculated as follow as follows:

$\Delta P_{\text {mix }}=\zeta \frac{\rho v^{2}}{2}$

where the parameter zeta is the resistance coefficient for each type of singularity loss (Pan et al., 2008).

\section{References}

Ahlstrm, P.-E., 1997. Towards a swedish repository for spent fuel. Nucl. Eng. Des. 176 (1), 67-74.

Al-Rawashdeh, M., Nijhuis, X., Rebrov, E.V., Hessel, V., Schouten, J.C., 2012. Design methodology for barrier-based two phase flow distributor. AIChE J. 58 (11), 3482-3493.

Amador, C., Gavriilidis, A., Angeli, P., 2004. Flow distribution in different microreactor scale-out geometries and the effect of manufacturing tolerances and channel blockage. Chem. Eng. J. 101 (1), 379-390.

Asakura, T., Hotoku, S., Ban, Y., Matsumura, M., Morita, Y., 2005. Technetium separation for future reprocessing. J. Nucl. Radiochem. Sci. 6 (3), 271-274.

Bascone, D., Angeli, P., Fraga, E.S., 2017. Mathematical modelling of intensified extraction for spent nuclear fuel reprocessing. In: Espua, A., Graells, M., Puigjaner, L., (Eds. ). Proceedings of the 27th European Symposium on Computer Aided Process Engineering - ESCAPE 27. Barcelona (Spain). pp. 355-360.

Becht, S., Franke, R., Geielmann, A., Hahn, H., 2009. An industrial view of process intensification. Chem. Eng. Process. 48 (1), 329-332.

Benedict, M., Pigford, T.H., Levi, H.W., 1980. Nuclear Chemical Engineering, second ed. McGraw Hill, New York.

Birkett, J.E., Carrott, M.J., Fox, O.D., Jones, C.J., Maher, C.J., Robeu, C.V., Taylor, R.J., Woodhead, D.A., 2007. Controlling neptunium and plutonium within single cycle solvent extraction flowsheets for advanced fuel cycles. J. Nucl. Sci. Technol. 44 (3), 337-343.

Carter, R.D., Kiel, G.R., Ridgway, K.R., 1968. Criticality handbook, vol. 1, Tech. rep., Atlantic Richfield Hanford Co., Report ARH-600.

CM Scientific.http://www.cmscientific.com/ (accessed 23.10.2017)

Commenge, J.M., Saber, M., Falk, L., 2011. Methodology for multi-scale design of isothermal laminar flow networks. Chem. Eng. J. 173 (2), 541-551.

Cross, W., Ramshaw, C., 1986. Process intensification: laminar flow heat transfer 64 293-301.

Dore, V., Tsaoulidis, D., Angeli, P., 2012. Mixing patterns in water plugs during water/ ionic liquid segmented flow in microchannels. Chem. Eng. Sci. 80, 334-341.

GAMS Development Corporation, 2013. General Algebraic Modeling System (GAMS) Release 24.2.1. Washington, DC, USA.

Geier, R., Browne, L., 1977. Solvent extraction equipment evaluation study. Part 1. Review of the literature (Tech. Rep.). BNWL-2186(PT.1), Battelle Pacific Northwest Labs., Richland, Wash. (USA).

Geier, R., Operation, H.A.P., 1957. Application of the pulse column to the Purex process. Hanford Atomic Products Operation.

Gonda, K., Matsuda, T., 1986. Solvent extraction calculation model for Purex process in pulsed sieve plate column. J. Nucl. Sci. Technol. 23 (10), 883-895.

Gonda, K., Miyachi, S., Fukuda, S., 1986. Stage efficiency for mixer-settlers process with chemical reactions. J. Nucl. Sci. Technol. 23 (3), 279-281.

Groenier, W.S., 1972. Calculation of the transient behavior of dilute-purex solvent extraction process having application to the reprocessing of $1 \mathrm{mfbr}$ fuels (Tech. rep). Oak Ridge National Laboratory.

Guillaume, B., Moulin, J.P., Maurice, C., 1984. Chemical properties of neptunium applied to neptunium management in extraction cycles of purex process. In: Extraction '84, Pergamon. pp. 31-45.

Herbst, R.S., Baron, P., Nilsson, M., 2011. Standard and advanced separation: PUREX processes for nuclear fuel reprocessing. In: Nash, K.L., Lumetta, G.J. (Eds.), Advanced separation techniques for nuclear fuel reprocessing and radioactive waste treatment. Woodhead Publishing Series in Energy Woodhead Publishing, pp. 141-175.

Hongyan, C., Taylor, R.J., Jobson, M., Masters, A.J., 2017. Simulation of neptunium extraction in an advanced purex process model improvement. Solvent Extr. Ion Exch. 35 (1), 1-18.

IAEA, 2008. Spent fuel reprocessing options. In: IAEA-TECDOC-1587.

Jiang, H., Wang, J.-A.J., 2016. Spent nuclear fuel system dynamic stability under normal conditions of transportation. Nucl. Eng. Des. 310, 1-14.

Jiao, C., Ma, S., Song, Q., 2013. Mass transfer characteristics in a standard pulsed sieveplate extraction column. Energy Procedia 39, 348-357.

Kashid, M.N., Agar, D.W., 2007. Hydrodynamics of liquid-liquid slug flow capillary microreactor: flow regimes, slug size and pressure drop. Chem. Eng. J. 131, 1-13.

Kashid, M.N., Gupta, A., Renken, A., Kiwi-Minsker, L., 2010. Numbering-up and mass transfer studies of liquid-liquid two-phase microstructured reactors. Chem. Eng. J. 158 (2), 233-240.

Kim, S.H., Park, S.B., Lee, S.J., Kim, J.G., Lee, H.S., Lee, J.H., 2013. Computer-assisted design and experimental validation of multielectrode electrorefiner for spent nuclear fuel treatment using a tertiary model. Nucl. Eng. Des. 257, 12-20.

Kim, S.H., Kim, J.H., Shin, C.H., Kim, J.K., Park, H.S., Kim, S.Y., 2014. A feasibility study on the criticality control method using radioactive vitrified forms for spent fuel storage. Nucl. Eng. Des. 280, 644-650.

Koltunov, V.S., 1974. Kinetika reaktsii aktinoidov (Kinetics of Actinide Reactions) Atomizdat, Moscow.

Kumar, S., Koganti, S.B., 2001. Modelling of np(iv) np(vi) distribution coefficients in 30 of. Chem. Technol. 8 (1), 41-43.

Law, J.D., Todd, T.A., 2008. Liquid-liquid extraction equipment (Tech. Rep. INL/CON08-15151). Idaho National Laboratory, United States.

Leclerc, A., Philippe, R., Houzelot, V., Schweich, D., de Bellefon, C., 2010. Gas liquid Taylor flow in square micro-channels: new inlet geometries and interfacial area tuning. Chem. Eng. J. 165 (1), 290-300.

Lee, J., Cho, D., Lee, M., Kook, D., Choi, H., Choi, J., Wang, L., 2012. Efficiency analyse of the candu spent fuel repository using modified disposal canisters for a deep geological disposal system design. Nucl. Eng. Des. 242, 433-444.

Mohamed, N.M., 2014. Direct reuse of spent nuclear fuel. Nucl. Eng. Des. 278, 182-189.

Natarajan, R., Pandey, N.K., Vijayakumar, V., Subbarao, R.V., 2012. Modeling and simulation of extraction flowsheet for FBR fuel reprocessing. Proc. Chem. 7, 302-308.

Pan, M., Tang, Y., Pan, L., Lu, L., 2008. Optimal design of complex manifold geometries for uniform flow distribution between microchannels. Chem. Eng. J. 137 (2), 339-346.

Pan, M., Tang, Y., Yu, H., Chen, H., 2009. Modeling of velocity distribution among microchannels with triangle manifolds. AIChE J. 55 (8), 1969-1982.

Qian, Y., Fei, W.Y., Wang, J.D., 1989. A study on mass transfer in pulsed sieve-plate extraction column. Chin. J. Chem. Eng. 4 (2), 218-228.

Ramshaw, C., 1983. HIGEE distillation-an example of process intensification. Chem. Eng. $389,13-14$.

Richardson, G.L., Swanson, J.L., 1975. Plutonium partitioning in the purex process with hydrazine stabilized hydroxylamine nitrate (Tech. rep). Hanford Engineering Development Laboratory.

Saber, M., Commenge, J.M., Falk, L., 2009. Rapid design of channel multi-scale networks with minimum flow maldistribution. Chem. Eng. Process. 48 (3), 723-733.

Saber, M., Commenge, J.M., Falk, L., 2010. Heat-transfer characteristics in multi-scale flow networks with parallel channels. Chem. Eng. Process. 49 (7), 732-739.

Scheiff, F., Mendorf, M., Agar, D., Reis, N., Mackley, M., 2011. The separation of immiscible liquid slugs within plastic microchannels using a metallic hydrophilic sidestream. Lab. Chip 11 (6), 1022-1029.

Seider, W.D., Seader, J.D., Lewin, D.R., 2004. Product and process design principles: synthesis, analysis, and evaluation. Wiley, New York.

Smith, R., 2005. Chemical Process Design and Integration. John Wiley \& Sons Ltd, United Kingdom.

Stankiewicz, A.I., Moulijn, J.A., 2000. Process intensification: Transforming chemical engineering. Chem. Eng. Progress New York 96 (1), 22.

Tachimori, S., 1994. Extra-m: a computing code system for analysis of the purex process with mixer settlers for reprocessing (Tech. rep.). Jpn. At. Energy Res. Inst.

Todd, T.A., 2008. Spent nuclear fuel reprocessing. In: Proc. of Nuclear Regulatory Commission Seminar.

Treybal, R.E. The economic design of mixer-settler extractors 5(4), 474-482.

Tsaoulidis, D., Angeli, P., 2015. Effect of channel size on mass transfer during liquid plug 
flow in small scale extractors. Chem. Eng. J. 262, 785-793.

Tsaoulidis, D., Dore, V., Angeli, P., Plechkova, N.V., Seddon, K.R., 2013. Flow patterns and pressure drop of ionic liquid water two-phase flows in microchannels. Int. J. Multiph. Flow 54, 1-10.

Tsaoulidis, D., Dore, V., Angeli, P., Plechkova, N.V., Seddon, K.R., 2013. Dioxouranium (VI) extraction in microchannels using ionic liquids. Chem. Eng. J. 227, 151-157.

Tsaoulidis, D., Dore, V., Angeli, P., Plechkova, N.V., Seddon, K.R., 2013. Extraction of dioxouranium(VI) in small channels using ionic liquids. Chem. Eng. Res. Des. 91 (4), 681-687.

Tsouris, C., Porcelli, J.V., 2003. Process intensification - has its time finally come? Chem. Eng. Progress New York 99 (10), 50.
Uchiyama, G., Hotoku, S., Fujine, S., 1998. Distribution of nitrous acid between tri-nbutyl phosphate/ n-dodecane and nitric acid. Solvent Extr. Ion Exch. 16 (5), 1177-1190.

Vandu, C.O., Liu, H., Krishna, R., 2005. Mass transfer from Taylor bubbles rising in single capillaries. Chem. Eng. Sci. 60 (22), 6430-6437.

Van Gerven, T., Stankiewicz, A., 2009. Structure, energy, synergy, time - the fundamentals of process intensification. Ind. Eng. Chem. Res. 48 (5), 2465-2474.

Vladimirova, M.V., Kulikov, I.A., Kuprii, A.A., 1992. Hydrolysis of TBP and TiAP in the presence of zirconium. At. Energy 73 (4), 788-792.

Xu, B., Cai, W., Liu, X., Zhang, X., 2013. Mass transfer behavior of liquid-liquid slug flow in circular cross-section microchannel. Chem. Eng. Res. Des. 91 (7), 1203-1211. 